\title{
Studi Perbandingan Transpirasi antar Pohon di Hutan Kota Malabar (Penelitian Pendahuluan untuk Solusi Pengelolaan Lahan Kering)
}

\author{
Comparison Study of Tree Transpiration in Malabar City Forest (A Preliminary Study for \\ Dryland Management Solution)
}

\author{
Rofinus Bu'u Nuwa ${ }^{1 *}$, Sama' Iradat Tito², Yani Quarta Mondiana ${ }^{3}$, \\ Poegoeh Prasetyo Rahardjo ${ }^{4}$ \\ ${ }^{1,3,4}$ Fakultas Kehutanan, Institut Pertanian Malang, Malang, Indonesia \\ ${ }^{2}$ Biologi FMIPA, Universitas Islam Malang, Malang, Indonesia \\ Corresponding Author: thambusno@gmail.com
}

\begin{abstract}
ABSTRAK
Kekeringan merupakan salah satu masalah serius yang sering muncul ketika musim kemarau tiba dan berkepanjangan. Dari aspek hidrometeorologi kekeringan timbul dan disebabkan oleh berkurangnya curah hujan selama periode tertentu. Tujuan dari penelitian ini adalah untuk mengetahui jenis pohon dengan transpirasi paling besar berdasarkan karakteristik daun dan hasil total transpirasi. Hasil penelitian ini menunjukkan pohon gymnospermae yang daun paling lebar yaitu daun pohon melinjo 1 yaitu lebar $5,3 \mathrm{~cm}$ dan jenis pohon angiospermae yang daunnya paling lebar yaitu daun pohon ketapang 2 yaitu lebar $18,4 \mathrm{~cm}$. Jenis pohon gymnospermae yang daun paling tebal yaitu daun pohon cemara norflok 1 dengan tebal daunya yaitu 0,049 $\mathrm{mm}$, sedangkan jenis angiospermae pohon dengan daun paling tebal yaitu daun pohon ketapang 3 dengan tebal daunnya itu 0,015 mm. Jumlah total daun paling banyak yaitu jenis glodokan sebesar 7809 . Pada jenis pohon gymnospermae rata-rata jumlah uap air yang dihasilkan paling banyak adalah pohon Melinjo dengan jumlah rata-rata $1.428,07 \mathrm{ml}$. Sedangkan pada jenis pohon angiospermae, pohon yang paling besar menghasilkan uap air yaitu Ketapang dengan nilai rata-rata 9.607,6 ml. Dari hasil pengamatan, peneliti menyimpulkan jenis pohon angiospermae yang paling banyak menghasilkan uap air yaitu jenis pohon Ketapang, karena dilihat dari panjang daun, lebar daun dan tipisnya daun sehingga pohon ketapang yang paling banyak menghasilkan uap air.
\end{abstract}

Kata kunci : Jenis Pohon, Tranpirasi, Karakteristik Daun, Total Transpirasi

\section{ABSTRACT}

Drought is a serious problem that often arises when the dry season arrives and the drought prolongs. From the hydrometeorological aspect, drought arises and is caused by reduced rainfall over a certain period. The purpose of this study was to determine the tree species with the greatest transpiration based on leaf characteristics and total transpiration results. The results of this study indicate Gymnosperms which have the widest leaves are melinjo 1 trees which are $5.3 \mathrm{~cm}$ wide and angiosperms which have the widest leaves, Ketapang 2 leaves which are $18.4 \mathrm{~cm}$ wide. Gymnosperms which have the thickest leaves are norflok 1 spruce with $0.049 \mathrm{~mm}$ thick, while angiosperms with the thickest leaves are ketapang 3 leaves with 0.015 $\mathrm{mm}$ thick leaves. The most total number of leaves, namely glodokan, is 7809. In the type of gymnosperms, the average amount of water vapor produced is the Melinjo tree with an average number of 1,428.07 $\mathrm{ml}$. Whereas in the angiosperms tree species, the largest tree that produces water vapor is Ketapang with an average value of $9,607.6 \mathrm{ml}$. From the observations, the researchers concluded that the type of angiosperms that produced the most water vapor was the Ketapang tree type, because it was seen from the length of the leaves, the width of the leaves and the thinness of the leaves so that the ketapang trees produced the most water vapor.

Keywords: Tree Species, Respiration, Leaf Characteristics, Total Transpiration

\section{PENDAHULUAN}

Kekeringan merupakan salah satu masalah serius yang sering muncul ketika musim kemarau tiba dan berkepanjangan. Banyak tempat di Indonesia mengalami masalah kekurangan air atau defisit air atau kekeringan, contohnya di Propinsi Nusa Tenggara Timur Kabupaten Nagekeo. Pada umumnya bencana kekeringan tidak dapat diketahui mulanya, namun dapat di katakan bahwa kekeringan terjadi saat air yang ada sudah tidak lagi mencukupi untuk kebutuhan sehari-hari. Kerusakan lahan dan dampak kerugian yang diakibatkan oleh kejadian kekeringan sangat luas dan kerugian ekonomi cukup besar. 
Evaporasi dan transpirasi berperan penting dalam siklus hidrologi, yang berperan bagi kelangsungan hidup organisme di bumi. Siklus air atau siklus hidrologi adalah sirkulasi air yang tidak pernah berhenti dari atmosfer ke bumi dan kembali ke atmosfer. $30 \%$ awan yang terbentuk adalah dari hasil transpirasi tanaman (Kramer, 1980).

Penelitian tentang studi perbandingan transpirasi antar pohon, untuk mengetahui jumlah uap air yang dihasilkan pada saat transpirasi ini diharapkan dapat dijadikan suatu cara atau solusi bagi daerah yang curah hujannya rendah untuk mengurangi musim kemarau berkepanjangan.

Informasi mengenai pohon transpirasi dilakukan dengan mengambil lokasi penelitian di Hutan Kota Malabar.

Penelitian ini bertujuan untuk mengetahui jenis pohon dengan transpirasi paling besar berdasarkan karakteristik daun dan hasil total transpirasi.

\section{MATERI DAN METODE}

\section{Rancangan}

\section{a. Lokasi dan Waktu}

Penelitian berlokasi di Hutan Kota Malabar, Kota Malang. Waktu Penelitian dilaksanakan pada bulan Juli sampai Agustus 2019.

\section{b. Alat dan Obyek}

Alat yang digunakan adalah Thermometer, Hygrometer,Pitameter, Hagamete r, Mikro meter, Lux meter, Hand tally counter, Plastik bening, Karet, Gelas ukur, Kamera, ATM.

Obyek yang diamati adalah proses penguapan air melalui daun dari 4 jenis pohon gymnospermae dan 4 jenis pohon angiospermae tingkat tiang.

Dari keempat jenis pohon gymnospermae dan angiospermae tersebut, masing-masing diambil 3 pohon. Jadi jumlah semua pohon gymnospermae dan angiospermae tersebut, terdapat sebanyak 24 pohon yang akan diteliti.

Dari 24 pohon tersebut, masing-masing diteliti 5 ranting daun untuk mengetahui berapa banyak proses penguapan air dari masingmasing pohon tersebut. Metode ini adalah metode analisis simulasi yang belum pernah dilakukan peneliti lain.

\section{c. Metode}

Metode penelitian ini adalah metode purposive sampling, survei dan observasi, dan bersifat kualitatif.

\section{d. Pengambilan dan Analisa Data}

Pengambilan data dan analisa data dilakukan dengan cara menghitung nilai ratarata hasil pengamatan pada tiap parameter pengamatan. Pengamatan tersebut antara lain meliputi :

1. Pengukuransuhu, kelembaban, dan intensitas cahaya

Pengukuran suhu menggunakan thermometer, pengukuran kelembaban menggunakan hygrometer, dan pengukuran intesitas cahaya menggunakan lux meter. Hasil tersebut kemudian di rata-rata.

2. Tinggi tanaman dan diameter pohon Adapun perhitungan dengan rumus :

Tinggi pohon $=\mathbf{~ ( b )}-(\mathbf{a})$

Setelah di dapat keliling lingkaran maka kemudian di bagi dengan rumus

$$
\frac{\text { keliling }}{\pi=3,14}
$$

3. Panjang daun, lebar daun, dan tebal daun.

Pengukuran panjang dan lebar daun menggunakan mistar, sedangkan untuk pengukuran tebal daun menggunakan mikrometer. Daun diambil dari masing-masing vegetasi. Hasil dari masing-masing vegetasi akan dirata-rata.

4. Jumlah daun total

Jumlah daun total dihitung dengan menggunakan Hand tally counter, daun yang dihitung yaitu jumlah daun keseluruhan pada pohon uji, dengan rumus :

Keterangan :

$$
\mathbf{T}=\mathbf{D}_{\mathrm{a}} \times \mathbf{R}_{\mathrm{a}}
$$

$\mathrm{T}=$ total ditemasi daun dalam satu pohon.

$\mathrm{D}_{\mathrm{a}}=$ banyaknya daun dalam satu ranting

$\mathrm{R}_{\mathrm{a}}=$ banyaknya ranting

5. Estimasi air dalam 1 pohon

Langkah-langkah estimasi air dalam 1 pohon adalah sebagai berikut:

a. Setiap pohon di bungkus 5 ranting daun uji selama 1 kali 24 jam untuk mengambil air hasil penguapan.

b. Air hasil penguapan akan di tampung di dalam plastik yang membungkus daun.

c. kemudian air tersebut di masukan di dalam gelas ukur agar peneliti bisa mengetahui jumlah air setiap daun uji 
d. Air hasil pengukuran dari gelas ukur akan dijumlah dengan daun total dalam satu pohon agar peneliti mengetahui jumlah total air hasil penguapan dalam 1 pohon dengan melihat jumlah daun total.

Dari hasil tersebut maka mudah untuk menentukan jenis pohon yang tingkat penguapannya tinggi rumus :

$$
\mathrm{Ta}=\frac{\mathrm{aR}}{\mathrm{Da}} \mathrm{Td}
$$

Keterangan :

$$
\begin{array}{ll}
\text { Ta } & : \text { Total air dalam Satu pohon } \\
\text { aR } & \text { : Jumlah total air dalam } 5 \text { ranting uji } \\
\text { Da } & \text { : Banyaknya daun Dalam } 1 \text { Ranting } \\
\text { Td } & \text { : Total Daun Dalam } 1 \text { pohon }
\end{array}
$$

\section{HASIL DAN PEMBAHASAN}

\section{Panjang Daun Lebar Daun dan Tebal Daun}

Peneliti melakukan pengukuran panjang, lebar, dan tebal daun, seperti pada tabel 1 dibawah.

Tabel 1. Hasil Pengukuran Panjang,Lebar dan Tebal Daun Tanaman Uji

\begin{tabular}{lllccc}
\hline No & Nama Vegetasi & Nama latin & $\begin{array}{c}\text { Panjang daun } \\
\text { (cm) }\end{array}$ & $\begin{array}{c}\text { Lebar } \\
\text { daun } \\
\text { (cm) }\end{array}$ & $\begin{array}{c}\text { Tebal daun } \\
\text { (mm) }\end{array}$ \\
\hline 1 & Cemara Norflok 1 & Araucaria heterophylla & 17,5 & 1,1 & 0,049 \\
2 & Cemara Norflok 2 & Araucaria heterophylla & 17,1 & 1,1 & 0,037 \\
3 & Cemara Norflok 3 & Araucaria heterophylla & 17,4 & 1,1 & 0,045 \\
4 & Cemara Laut 1 & Casuarina equisetifolia & 7 & 0 & 0,024 \\
5 & Cemara Laut 2 & Casuarina equisetifolia & 4,6 & 0 & 0,021 \\
6 & Cemara Laut 3 & Casuarina equisetifolia & 5,2 & 0 & 0,024 \\
7 & Melinjo 1 & Gnetum gnemon & 16,6 & 5,3 & 0,012 \\
8 & Melinjo 2 & Gnetum gnemon & 16,5 & 5,1 & 0,011 \\
9 & Melinjo 3 & Gnetum gnemon & 16,2 & 4,9 & 0,09 \\
10 & Pinus 1 & Pinus mercusii & 13,8 & 0 & 0,012 \\
11 & Pinus 2 & Pinus mercusii & 13,6 & 0 & 0,012 \\
12 & Pinus 3 & Pinus mercusii & 13,6 & 0 & 0,012 \\
13 & Mahoni 1 & Swietenia mahagoni & 30 & 10,4 & 0,013 \\
14 & Mahoni 2 & Swietenia mahagoni & 27 & 9,5 & 0,011 \\
15 & Mahoni 3 & Swietenia mahagoni & 24,9 & 10,1 & 0,010 \\
16 & Gelodokan 1 & Polyalthia longifolia & 15,5 & 4,4 & 0,012 \\
17 & Gelodokan 2 & Polyalthia longifolia & 13,3 & 5,7 & 0,013 \\
18 & Gelodokan 3 & Polyalthia longifolia & 16,2 & 5,5 & 0,09 \\
19 & Ketapang 1 & Terminalia catappa & 40,4 & 16,1 & 0,012 \\
20 & Ketapang 2 & Terminalia catappa & 45,3 & 18,4 & 0,015 \\
21 & Ketapang 3 & Terminalia catappa & 41,7 & 16,3 & 0,013 \\
22 & Mangga 1 & Mangifera sp. & 26,2 & 5,9 & 0,013 \\
23 & Mangga 2 & Mangifera sp. & 22,8 & 3,6 & 0,010 \\
24 & Mangga 3 & Mangifera sp. & 24,4 & 4,9 & 0,012 \\
\hline
\end{tabular}

Hasil penelitian ini menunjukkan pohon gymnospermae yang daun paling lebar yaitu daun pohon melinjo 1 yaitu lebar 5,3 cm dan jenis pohon angiospermae yang daunnya paling lebar yaitu daun pohon ketapang 2 yaitu lebar $18,4 \mathrm{~cm}$. Daun paling tebal jenis pohon gymnospermae yaitu daun pohon cemara norflok 1 dengan tebal daunya yaitu $0,049 \mathrm{~mm}$, sedangkan daun paling tebal pohon jenis angiospermae yaitu daun pohon ketapang 3 dengan tebal daunnya itu $0,015 \mathrm{~mm}$.

Proses transpirasi dipengaruhi oleh berbagai faktor internal dan eksternal. Faktor internal antara lain seperti ukuran daun, tebal tipisnya daun, tebal lapisan lilin, jumlah rambut daun, jumlah, bentuk 
dan lokasi stomata, termasuk pula umur jaringan, keadaan fisiologis jaringan dan laju metabolisme (Dwidjoseputro, 1994). Faktor-faktor eksternal antara lain meliputi radiasi cahaya, suhu, kelembaban udara, angin dan kandungan air tanah (Dardjat dan Arbayah, 1996). Selain itu juga dipengaruhi oleh gradient potensial air antara tanah, jaringan dan atmosfer, serta adanya zat-zat toksik di lingkungannya. Menurut Goldworthy dan Fisher (1992), pembukaan stomata dipengaruhi oleh $\mathrm{CO}_{2}$, cahaya, kelembaban, suhu, angin, potensial air daun dan laju fotosintesis. Mekanisme kontrol laju kehilangan air dapat dilakukan dengan mengontrol laju metabolisme, adaptasi struktural daun yang dapat menekan laju kehilangan air, termasuk di antaranya mengatur konduktivitas stomata.

Loveless (1991, dalam Suyitno, 2012) menyatakan bahwa luas daun pada tumbuhan berpengaruh terhadap laju transpirasi. Hal ini karena daun yang luas memiliki jumlah stomata yang banyak, sehingga mengakibatkan tingginya laju transpirasi.

Tabel 2. Estimasi Air Hasil Transpirasi dalam Satu Pohon Masing-Masing Vegetasi

\begin{tabular}{|c|c|c|c|c|c|c|c|c|c|c|c|}
\hline NO & $\begin{array}{c}\text { JENIS } \\
\text { VEGETASI }\end{array}$ & $\begin{array}{l}R 1 \\
(\mathrm{~m})\end{array}$ & $\begin{array}{l}R 2 \\
\text { (m) }\end{array}$ & $\begin{array}{l}\text { R3 } \\
(\mathrm{m})\end{array}$ & $\begin{array}{l}\text { R4 } \\
(\mathrm{m})\end{array}$ & R5 & $\mathrm{aR}$ & $\mathrm{Da}$ & Td & $\begin{array}{l}\mathrm{Ta} \\
(\mathrm{ml})\end{array}$ & $\begin{array}{l}\text { Rata- } \\
\text { rata }\end{array}$ \\
\hline \multirow{3}{*}{1} & Cemara Norflok 1 & 1 & 2 & 1 & 3 & 1 & 8 & 54 & 6534 & 914,76 & \multirow{3}{*}{850,12} \\
\hline & Cemara Norflok 2 & 2 & 2 & 1 & 2 & 1 & 8 & 65 & 6630 & 795,6 & \\
\hline & Cemara Norflok 3 & 1 & 1 & 2 & 2 & 1 & 7 & 42 & 5250 & 840 & \\
\hline \multirow{3}{*}{2} & Cemara Laut 1 & 3 & 3 & 2 & 3 & 3 & 14 & 35 & 4340 & 1736 & \multirow{3}{*}{$1.226,79$} \\
\hline & Cemara Laut 2 & 3 & 1 & 2 & 2 & 1 & 9 & 31 & 3286 & 952,94 & \\
\hline & Cemara Laut 3 & 1 & 2 & 3 & 2 & 2 & 10 & 54 & 5508 & 991,44 & \\
\hline \multirow{3}{*}{3} & Melinjo 1 & 4 & 2 & 3 & 1 & 3 & 13 & 21 & 2520 & 1537,2 & \multirow{3}{*}{$1.428,07$} \\
\hline & Melinjo 2 & 5 & 3 & 2 & 1 & 1 & 12 & 20 & 2660 & 1596 & \\
\hline & Melinjo 3 & 2 & 1 & 1 & 3 & 2 & 9 & 19 & 2449 & $1.151,03$ & \\
\hline \multirow{3}{*}{4} & Pinus 1 & 1 & 1 & 3 & 2 & 2 & 9 & 38 & 3914 & 900,22 & \multirow{3}{*}{945,84} \\
\hline & Pinus 2 & 2 & 1 & 2 & 2 & 1 & 8 & 41 & 4551 & 994,84 & \\
\hline & Pinus 3 & 1 & 1 & 2 & 3 & 1 & 8 & 44 & 5236 & 942,48 & \\
\hline \multirow{3}{*}{5} & Mahoni 1 & 7 & 3 & 4 & 3 & 6 & 23 & 9 & 1107 & $2.822,85$ & \multirow{3}{*}{$3.063,95$} \\
\hline & Mahoni 2 & 6 & 8 & 2 & 7 & 4 & 27 & 10 & 1170 & 3.159 & \\
\hline & Mahoni 3 & 10 & 2 & 6 & 8 & 4 & 30 & 15 & 1605 & 3.210 & \\
\hline \multirow{3}{*}{6} & Gelodkan 1 & 10 & 10 & 3 & 7 & 3 & 33 & 54 & 6534 & $3.985,74$ & \multirow{3}{*}{$3.615,99$} \\
\hline & Gelodkan 2 & 7 & 3 & 8 & 6 & 3 & 27 & 57 & 7809 & $3.670,23$ & \\
\hline & Gelodkan 3 & 4 & 5 & 6 & 3 & 6 & 24 & 48 & 6384 & 3.192 & \\
\hline \multirow{3}{*}{7} & Ketapang 1 & 7 & 8 & 13 & 8 & 9 & 45 & 7 & 1008 & $6.471,36$ & \multirow{3}{*}{$9.607,6$} \\
\hline & Ketapang 2 & 15 & 15 & 30 & 6 & 13 & 79 & 7 & 798 & $9.001,44$ & \\
\hline & Ketapang 3 & 31 & 25 & 15 & 10 & 8 & 89 & 10 & 1500 & 13.350 & \\
\hline \multirow{3}{*}{8} & Mangga 1 & 30 & 23 & 17 & 4 & 5 & 79 & 22 & 2794 & $10.030,46$ & \multirow{3}{*}{$7.792,82$} \\
\hline & Mangga 2 & 8 & 5 & 3 & 6 & 2 & 24 & 19 & 2527 & $3.184,02$ & \\
\hline & Mangga 3 & 30 & 23 & 18 & 6 & 7 & 84 & 20 & 2420 & 10.164 & \\
\hline
\end{tabular}

\section{Keterangan :}

Ta : Total air hasil transpirasi dalam satu pohon

aR : Jumlah total air dalam 5 ranting uji

$\mathrm{Da} \quad$ : Banyaknya daun dalam 1 Ranting

Td : Total daun dalam 1 pohon 


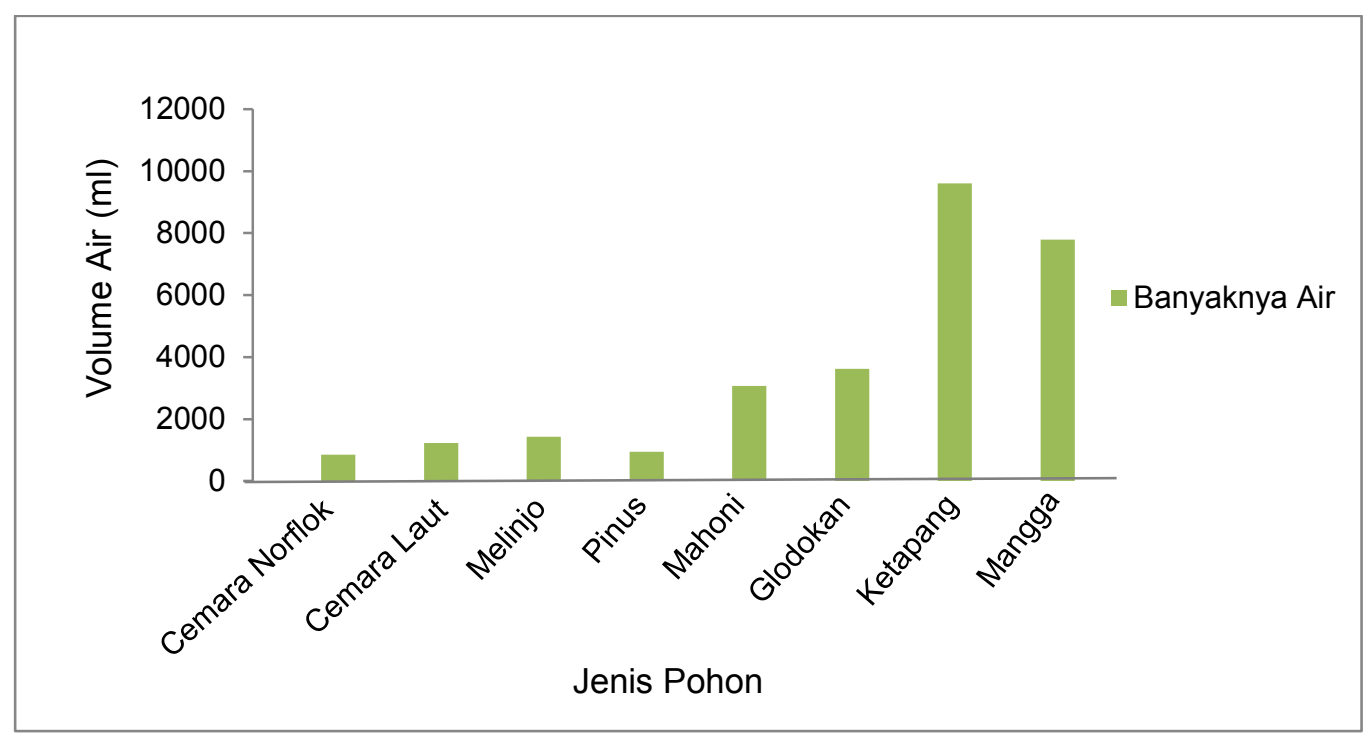

Gambar 1. Estimasi Air Hasil Transpirasi dalam Satu Pohon Masing-Masing Jenis Pohon

\section{Jumlah Daun Total}

Jumlah daun total dari jenis pohon gymnospermae maupun angiospermae masing-masing memiliki jumlah total daun dalam satu pohon yang berbedabeda sehingga peneliti perlu menghitung jumlah total daun dari masing-masing vegetasi yang nantinya membantu peneliti dalam perhitungan mengenai banyaknya air yang diuapakan dari setiap pohon.

\section{Estimasi Air Hasil Transpirasi Dalam Satu Pohon}

Berdasarkan tabel estimasi air dalam satu pohon, masing masing vegetasi yang diuji didapat berdasarkan jumlah air dalam 5 ranting uji dibagi banyaknya daun dalam satu ranting sehingga peneliti pengetahui berapa banyak hasil penguapan tiap daun yang nantinya dikalikan dengan total daun dalam 1 pohon untuk mendapatkan total air dalam satu pohon.

Pada jenis pohon gymnospermae ratarata jumlah uap air yang dihasilkan paling banyak adalah pohon Melinjo dengan jumlah rata-rata $1.428,07 \mathrm{ml}$. Sedangkan pada jenis pohon angiospermae, pohon yang paling besar menghasilkan uap air yaitu Ketapang dengan nilai rata-rata 9.607,6 ml.

Dari hasil pengamatan, peneliti menyimpulkan jenis pohon angiospermae yang paling banyak menghasilkan uap air yaitu jenis pohon Ketapang, karena dilihat dari panjang daun, lebar daun dan tipisnya daun sehingga pohon ketapang yang paling banyak menghasilkan uap air.

\section{KESIMPULAN}

Berdasarkan 24 pohon yang diteliti, Jenis pohon dengan transpirasi paling besar adalah jenis pohon Ketapang dengan jumlah rata-rata uap air 9.607,6 $\mathrm{ml}$ sedangkan jumlah transpirasi uap air paling rendah adalah jenis tumbuhan Cemara Norflok dengan jumlah rata-rata $850,12 \mathrm{ml}$.

Berdasarkan pengukuran karakteristik berdasarkan Lebar daun, panjang daun dan ketebalan daun paling besar adalah daun ketapang dengan panjang $45,3 \mathrm{~cm}$, lebar $18,4 \mathrm{~cm}$ dan tebal daun 0,015 $\mathrm{mm}$. Panjang daun, lebar daun dan tebal tipis daun mempengaruhi jumlah rata-rata transpirasi uap air. 


\section{DAFTAR PUSTAKA}

Dardjat S. dan Arbayah S. 1996. Fisiologi Tumbuhan. Depertemen Pendidikan dan Kebudayaan. Jakarta.

Dwidjoseputro. 1994. Pengantar Fisiologi Tumbuhan. Gramedia Pustaka Utama. Jakarta.

Goldsworthy, P . R. dan Fisher, N . M. 1992. Fisiologi Tanaman Budidaya Tropik. Gajah Mada University Press. Yogyakarta.

Kramer, P.J. 1980. Plant and Solo Water Relationship; A modern synthesis. Tata Mc Graw Hill.

Suyitno. 2012. Perbandingan jumlah stomata pada bagian abaksial dan adaksial.

http://www.pertanian.untagsmd.ac.id/wpcontent/uploads/2012/ 06/Proses_Transpirasi_PadaTanaman Bab IX.pdf. Diakses pada tanggal 15 Mei 2019. 